\title{
Experimental Studies on Machining EN45 Steel under Dry and MQL using Uncoated Inserts
}

\author{
Kosaraju Satynarayana ${ }^{1, *}$, Gayam Sreenivas Reddy²,, Chitimilla Srikar $^{2}$, Janaswami Gnyaneshwar ${ }^{2}$, Yedla $_{\text {Shyam }}$ \\ Prasad $^{2}$, Kumkuma Rajkiran ${ }^{3}$
}

${ }^{1}$ Assoc.Professor, GRIET, Mechanical Engineering Department, Hyderabad, India.

${ }^{2}$ UG Student, GRIET, Mechanical Engineering Department, Hyderabad, India.

${ }^{3}$ PG Student, GRIET, Mechanical Engineering Department, Hyderabad, India

\begin{abstract}
In owe to the global concern of environment growth and green production acts with use biodegradable and low consumption of lubrications the present paper deals use of MQL in turning EN 45 steel. Literacy over the use of effective production practices increases the efficiency of surface integrity and economical effect of production. With this aspect, the present study deals with of surface roughness characteristic generated while turning EN 45 graded spring steel with uncoated CNMG insert under MQL condition. A total of 27 experiments are performed on a CNC lathe under both Dry and MQL conditions. Surface roughness produced with varying in machining parameter of cutting speed $(75,100,125 \mathrm{~m} / \mathrm{min})$, feed rate $(0.1,0.2,0.3 \mathrm{~mm} / \mathrm{rev})$ and depth of cut $(0.3,0.6,0.9 \mathrm{~mm})$. Effect of induvial parameter over surface roughness is been clearly pictured out with the graphical representation with comparison under both DRY and MQL conditions. A mathematical model was generated with the experimental results for prediction of roughness within the limits of parameters. ANOVA analysis, feed shows a high contribution towards the surface roughness.
\end{abstract}

\section{Introduction}

With globally growth in production rate has simultaneously increased the use of lubricants accordingly to the production rate. This leads in increases in threats created by these lubrications while their disposing. Use of large amount of lubrication does not only effect with ecological imbalance but also in product cost. As production, maintenance, storage, usage techniques and disposable costs dealing with these lubrications shows direct impact on product cost. In order to overtake these obsolete practices, new practices have been come into existence. Use of low amount of lubrication is one of these techniques in which the lubrication is used in very micro levels. It is termed to be as near-by-dry machining, micro-level lubrication, minimum quantity lubrication and air-mist lubrication. In this process the lubricating fluid is sprayed on the shearing zone of the tool and workpiece blended with pressured dry air. An amount of $5 \mathrm{ml} / \mathrm{hr}$ to $500 \mathrm{ml} / \mathrm{hr}$ of lubrication is sprayed over the cutting zone. This results almost $20 \mathrm{l} / \mathrm{hr}$ flood lubricating process. Consequently use of this MQL has improves the surface integrity and also increase the tool life. Air pressure assist in chip breakage and carrying out the heat while the lubricant contributed in decreasing the friction reduction while turning and concludes with temperature reduction and low cutting forces.
For easy disposable methods bio-degradable oils extracted from vegetables, minerals, animal fats and cooked oils are being practiced. As these oils can be easily disposable without any further purification methods, use of bio-degradable oils are recommended by Environmental Protection Agencies (EPA) and Global Environmental Facilities (GEF). Use of water as lubrication was the oldest practice which was introduced by Taylor in around 1907's [1]. Further these water quantity was decreased by mixing the additives of water based oils with this water. After few decades in order to obtain the best of surface integrity, usage of plain straight cut oils came into practice. With the outbreak of industrial revolution act 3 in year 1969, establishment of industries has increased. Then after the threat of the lubricant disposable has directly shown in water bodies, air and environment pollution. Cutting lubricants have then categorized according to the terms like toxicity rate, bio-degradability, acidic-basic $(\mathrm{pH})$ nature, and recyclability, corrosive inheriting rate and hazard grades.

With the increasing in the citations over the MQL usage by industries and production departments, research over MQL grab the attention of researchers [2]. sharma[3] experimental stated that MQL can be used from a range of $5 \mathrm{ml} / \mathrm{hr}$ to $500 \mathrm{ml} / \mathrm{hr}$. on this factor, research have been followed with change in MQL fluids and change in flow 
rates of this MQL fluids. Lohar et al [4] has investigated the effect of flow rate of MQL over AISI 4340. Investigation was performed with $10 \mathrm{ml} / \mathrm{hr}, 20 \mathrm{ml} / \mathrm{hr}$ and $100 \mathrm{ml} / \mathrm{hr}$ flow rates with 6 bars of air pressure. Dhar et al [5] conducted an experimental turning over AISI 4340 with emulsifying oil at a flow rate of $60 \mathrm{ml} / \mathrm{hr}$ at 7 bar pressure. The same author again conducted the experiment over AISI 1040 with same flow rates [6] . In both the experimental runs, author could state the contribution of MQL over surface integrity.

Further paper was proceeded with use of optimizing techniques. The general optimizing tool that are prevailing in the use optimizing fields are ANNOVA, Taguchi, grey relation methods, mathematical modelling, which are further proceeded to the higher level with the use of artificial techniques of artificial intelligence and artificial neural networking. Lin et al[7] experimentally investigated the surface roughness of austenitic steel and optimized the machining parameters using ANOVA. In addition to anova, signal to noise ratio is used to find the machine parameter performance effect on surface roughness in terms of percentage contribution ( $\%$ cont)

In the present study a total of 27 experiments are perform on EN45 material with uncoated tool under dry and MQL condition to study the effect of process parameter. In addition to that ANOVA analysis was also performed to know the effect of process parameter during machining.

\section{Experimentation}

EN 45 is a spring steel material that has an ability to withstand to torsional effects without breakage up to its ultimate level. Material has been procured with the commercial sources and undergone heat treatment and chemical treatment. The chemical analysis report in Table 1 has met with the standards of the composition. STRUB VULCAN FUTURA CF10 90405 MQL fluid used while machining. Using the machining parameters in Table 2 L27 orthogonal array has been produces using MINITAB 18.

Table 1. EN 45 chemical analysis.

\begin{tabular}{|l|l|l|l|l|l|}
\hline Elements & $\mathrm{C}$ & $\mathrm{Si}$ & $\mathrm{Mn}$ & $\mathrm{P}$ & $\mathrm{S}$ \\
\hline $\mathrm{Wt} \%$ & 0.599 & 1.805 & 0.875 & 0.019 & 0.009 \\
\hline
\end{tabular}

Table 2. Machining parameters and their limits

\begin{tabular}{|l|l|l|l|l|}
\hline \multirow{2}{*}{ Parameters } & \multirow{2}{*}{$\begin{array}{l}\text { Notation and } \\
\text { units }\end{array}$} & \multicolumn{3}{|c|}{ Level } \\
\cline { 3 - 5 } & & 1 & 2 & 3 \\
\hline Speed & $\mathrm{v}(\mathrm{m} / \mathrm{min})$ & 75 & 100 & 125 \\
\hline Feed & $\mathrm{f}(\mathrm{mm} / \mathrm{rev})$ & 0.1 & 0.2 & 0.3 \\
\hline Depth Of Cut & $\mathrm{d}(\mathrm{mm})$ & 0.3 & 0.6 & 0.9 \\
\hline
\end{tabular}

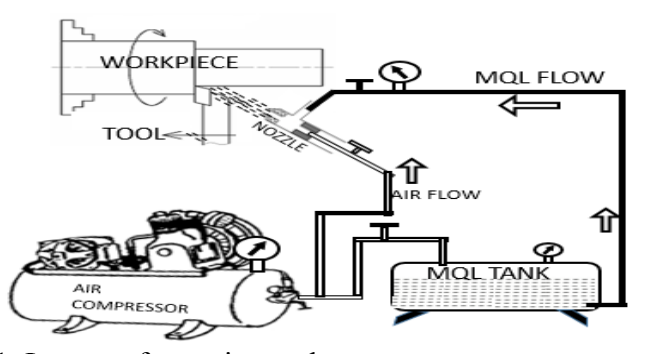

Fig. 1. Layout of experimental set-up

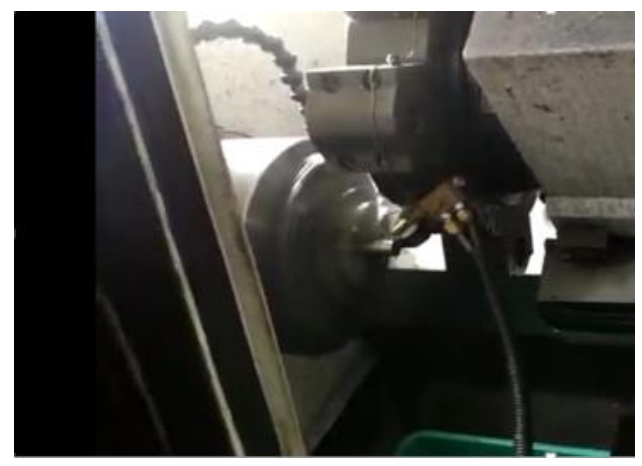

Fig. 2. Experimental Set-up

\section{Analysis of Results}

\subsection{Effect of speed on surface roughness}

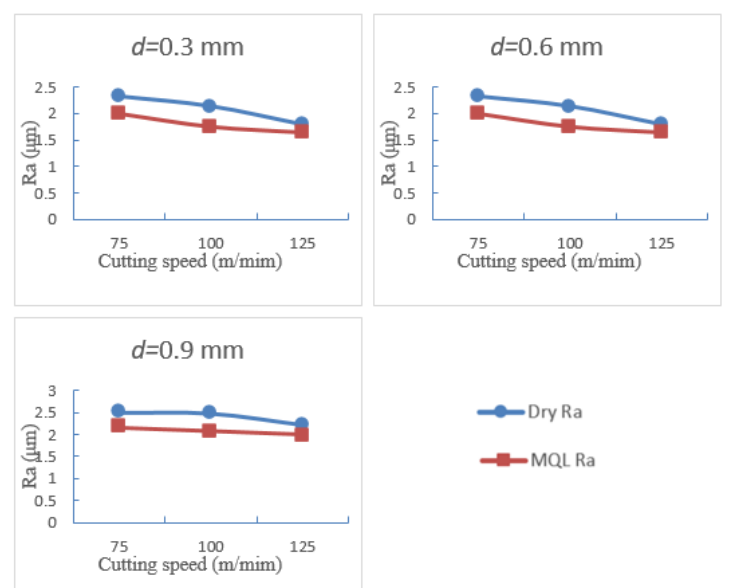

Fig. 3 Variation of surface roughness wrt speed

Cutting speed is termed as the rotational speed in turning operation. It pays a prominent role that deals with the surface roughness, tool wear and tangential force effect. In this experimental process, graph plotted within the speed and surface roughness. It states that higher the speed, the better the surface roughness. This is only applicable for low feed rate criteria [8].

\subsection{Effect of feed on surface roughness}

The rate of tool advancement through the workpiece while turning is termed as feed. Feed contributed a high role in surface roughness and material removal rate [9]. From the experimental process it can be clearly studied that feed is one of the major factor effecting the surface roughness. From the lots plotted in Fig 4 it is clear that 
higher the feed rate, the more the surface roughness. Higher feed rate created tool flank wear. Flank wear of the tool forms its indentation grooves over the workpiece which results in threads pattern structure on surface. Tool wear caused by feed rate is technically called as "burn out" [10] or "tearing the tool"

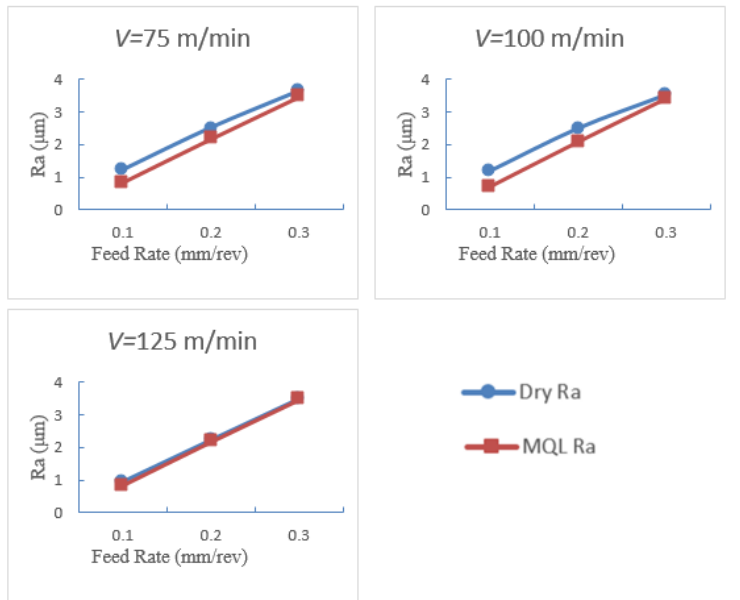

Fig. 4 Variation of surface roughness wrt feed rate

\subsection{Effect of depth of cut over surface roughness}

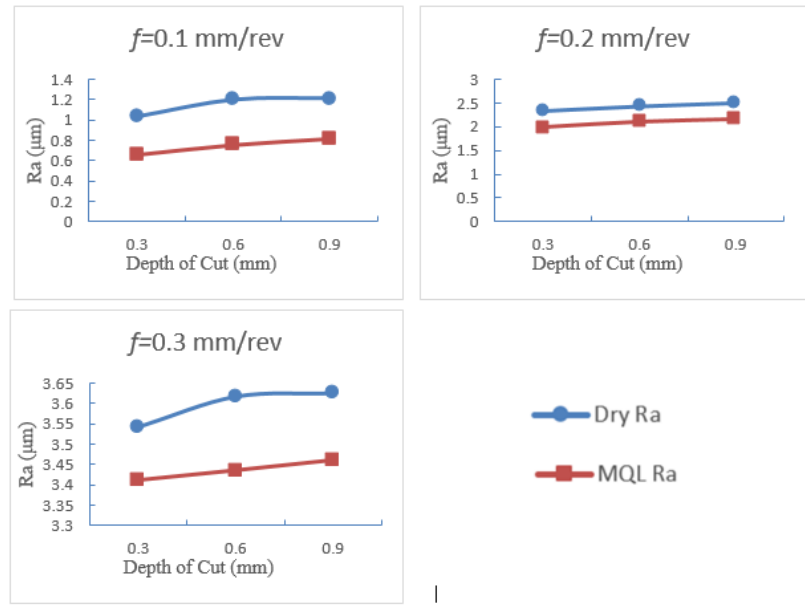

Fig.5 Variation of surcace roughness wrt depth of cut

Amount of tool penetration into the workpiece towards the centre axis of it, is known as depth of cut. Depth of cut contributed in the amount of material removal rate and surface roughness. The higher the depth, the more the material can be removal in advancement one revolution. Usually high speed are prominent in light material as they don't show effect over the tool tip [11] and low speed on hard to cut materials [12]

\section{Mathematical model and ANOVA}

Mathematical modelling is one of the technique to find out the machining characteristics with respect to machining parameters by a sequential formula generated among them. From the research by lodge in 1907 [13] to recent research of 2019 by Fathallah [14], mathematical modelling generation cleared the path for the industrial team to predict the surface roughness using these mathematical formulas. Utilizing the experimental values, the mathematical equation has been generated in Minitab 18 software. Fit regression technique for formulation given by the equation 1 and 2. R-sq and Rsq(adj) values near to $100 \%$ in both the equations therefore these equation may be utilized for the prediction of the values within the limit of the Table 2 .

Dry ra $=0.520-0.01025 \mathrm{v}+11.57 \mathrm{f}+0.160 \mathrm{~d}+0.01333$

$\mathrm{v}^{*} \mathrm{f}+0.00308 \mathrm{v} * \mathrm{~d}-0.764 \mathrm{f} * \mathrm{~d}$

R-sq $=85.89 \%$ and R-sq (adj) $=81.66 \%$

MQL $R a=0.02-0.0006 \mathrm{~V}-3.34 \mathrm{f}+2.20 \mathrm{~d}+0.1024$

$V^{*} f-0.0302 V^{*} d+8.37 f^{*} d$

$R-s q=99.58 \%$ and R-sq (adj) $=99.45 \%$

ANOVA is one tool to determine the most significant process parameter. The following are the outcome values of ANOVA performed over MINITAB software. It clearly shown that feed is the factor that contributes a high level compared with other parameters wrt the table 3 shown

Table 3. ANOVA result for roughness

\begin{tabular}{|l|l|l|l|l|l|l|}
\hline Source & DF & $\begin{array}{l}\text { Adj } \\
\text { SS }\end{array}$ & $\begin{array}{l}\text { Adj } \\
\text { MS }\end{array}$ & $\begin{array}{l}\text { F- } \\
\text { Value }\end{array}$ & $\begin{array}{l}\text { P- } \\
\text { Value }\end{array}$ & $\begin{array}{l}\text { \% of } \\
\text { cont }\end{array}$ \\
\hline Regression & 6 & 28.41 & 4.73 & 787.8 & 0.001 & \\
\hline$v$ & 1 & 0.090 & 0.09 & 15.13 & 0.001 & 8.95 \\
\hline$f$ & 1 & 0.776 & 0.77 & 129.2 & 0.001 & 76.51 \\
\hline$d$ & 1 & 0.001 & 0.013 & 0.22 & 0.641 & 0.12 \\
\hline$v^{*} f$ & 1 & 0.013 & 0.01 & 2.22 & 0.152 & 1.31 \\
\hline$v^{*} d$ & 1 & 0.006 & 0.006 & 1.06 & 0.315 & 0.63 \\
\hline$f^{*} d$ & 1 & 0.006 & 0.006 & 1.05 & 0.318 & 0.62 \\
\hline Error & 20 & 0.120 & 0.006 & & & 11.8 \\
\hline Total & 26 & 28.53 & & & & 100 \\
\hline
\end{tabular}

\section{Conclusions}

The experimental investigation on machining EN45 steel under Dry \& MQL condition has been performed with varying in speed, feed and depth of fut. A total of 27 experiments are performed in both the case of turning i.e, Dry and MQL to study the effect of parameters. Effect of machining parameters over surface roughness is clearly explained with graphical representation. Mathematical model has been generated in order for ease of prediction of surface roughness. ANOVA analysis has been performed using experiment data using tool MINITAB. The following are the observation that are evolved during the process

1. MQL contributes in improvement of surface roughness compared to that of dry conditional surface roughness.

2. Increasing in feed rate will increases the surface roughness. 
3. Increase in speed will reduces the surface roughness

4. Increase in depth of cut will increase the surface roughness.

5. Mathematical model has been generated from the experimental results to predict the results.

6. From ANOVA analysis, feed shows a high contribution towards the surface roughness.

\section{References}

1. Taylor, Frederick Winslow, American society of mechanical engineers, 23, (1906).

2. Hadad, M. J., Tawakoli, T., Sadeghi, M. H., \& Sadeghi, Int. J. Mach. Tools Manuf, 54, 1017(2012)

3. Sharma, V. S., Dogra, M., \& Suri, N. M, Int. J. Mach. Tools Manuf, 49(6), 435-453, (2009),

4. Lohar, D. V., \& Nanavaty, C. R. Int. J. ind. eng. manag. Sci, 3(3), 102-106, (2013)

5. Suresh Kumar T, Sankar V, 2011 IEEE India Conference, INDICON, 2011

6. Dhar, N. R., Islam, M. W., Islam, S., \& Mithu, M. A. H. J. Mater. Process. Technol. 171(1), 93-99. (2006).

7. Lin, T. R, Int J Adv Manuf Tech, 19(5), 330-335. (2002)

8. k- Zheng, G., Cheng, X., Li, L., Xu, R., \& Tian, Y., J Mech Sci Technol, 33(1), 341-349. (2019)

9. Kumar, S. L. Measurement, 140, 538-547 (2019).

10. Kataoka, R., \& Shamoto, E. Precis. Eng. 55, 322329 (2019)

11. Bankupalli, P.T., Srikanth Babu, V., Suresh Kumar. T, Int J of App Engg Res., 10(16), 2015

12. Das, A., Patel, S. K., \& Das, S. R. Mech. Ind, 20, 506. (2019).

13. Lodge, Oliver. "Physics and Chemistry." (1907): 414

14. Fathallah, B., Saidi, R., Dakhli, C., Belhadi, S., \& Yallese, M., Int. J. Ind. Eng. Comput, 10(4), 557576, (2019). 